\title{
UMA ANÁLISE DA TEMÁTICA HISTÓRIA E CULTURA INDÍGENA NO ENSINO DE GEOGRAFIA: REFLEXÕES A PARTIR DA REGIÃO METROPOLITANA DO RECIFE
}

\author{
João Luiz da Silva Vieira ${ }^{1}$ \\ Wedmo Teixeira Rosa ${ }^{2}$
}

\begin{abstract}
Resumo: A lei 11.645/2008 instituiu a obrigatoriedade da discussão da temática da História e Cultura afro-brasileira e indígena nas salas de aula da educação básica de todo território nacional. A partir desse pressuposto, esta pesquisa visa discutir não só a lei, mas também os demais documentos que alicerçam e promovem a temática indígena na rede estadual de ensino em Pernambuco. Além disso, também é feito um questionamento sobre a real aplicação da lei nas escolas, sobretudo no componente curricular Geografia. Para tanto, foram realizadas pesquisas bibliográficas e documentais, além de entrevistas com sujeitos considerados relevantes para a pesquisa, contribuindo numa articulação entre literatura acadêmica, documentos e experiências. Foi constatado que não há um forte engajamento voltado para a temática nem nas escolas nem nos principais órgãos estaduais responsáveis por sua implementação, deixando uma lacuna no que se refere a história e cultura indígena na educação básica.
\end{abstract}

Palavras-chave: Lei 11.645/2008; Relações Étnico-raciais; História e Cultura Indígena; Ensino de Geografia; Região Metropolitana do Recife.

\section{AN ANALYSIS OF THE INDIGENOUS THEMATIC HISTORY AND CULTURE: REFLEXIONS FROM THE METROPOLITAN REGION OF RECIFE}

\begin{abstract}
The law 11.645/2008 instituted the obligatoriness of the discussion about the thematic of Afro-Brazilian and indigenous history and culture in the classrooms of basic education in national territory. From this assumption, this research aims to discuss not just the law, but also the others documents which support and promote the indigenous thematic in the state educational system in Pernambuco. Furthermore, is also made a questioning about the real application of the law in the schools, especially in the Geography curricular component. Therefore, bibliographic and documental researches were made, besides a documentary research and interviews with subjects considered relevant to the research, contributing in an articulation between the academic literature, documents and experiences. It was verified that there is not a strong engagement focused to the theme, not in the
\end{abstract}

\footnotetext{
${ }^{1}$ Mestrando em Geografia pela Universidade Federal de Pernambuco (UFPE). joao.luiz.gnr@gmail.com.

${ }^{2}$ Docente do Instituto Federal de Pernambuco (IFPE) - Campus Recife. wedmo@ recife.ifpe.edu.br

Estudos Geográficos, Rio Claro, 17(1): 217-233, jan./jun. 2019 (ISSN 1678-698X) http://www.periodicos.rc.biblioteca.unesp.br/index.php/estgeo
} 
schools or in the main state public agencies responsible for its implementation, leaving a gap as regards to the indigenous history and culture in the basic education.

Keywords: Law 11.645/2008; Ethnic-racial Relations, Indigenous History and Culture; Education of Geography, Metropolitan Region of Recife.

\section{INTRODUÇÃO}

O ensino de relações étnico-raciais na Geografia se faz muito relevante, visto que a população brasileira é composta por vários grupos: brancos, indígenas, negros, ciganos, mestiços, pardos, entre outros. Cada um desses grupos é importante na formação territorial do país, na construção de cidades, na economia e em outros tantos assuntos nos quais a Geografia e as questões étnico-raciais se intersectam.

Para garantir que especificidades tão significativas sejam discutidas em sala de aula foram criadas leis, frutos das lutas de movimentos sociais durante o terceiro quarto do século $\mathrm{XX}$, que trouxeram o debate étnico-racial à sala de aula. Primeiro, a lei 10.639/03, que estabeleceu a obrigatoriedade do ensino da história e cultura afrobrasileira. Em 2008, foi promulgada a lei 11.645, que ampliou a lei anterior, instituindo também a obrigatoriedade do ensino da história e cultura indígena, sendo essa temática basal na análise para este artigo. Ambas as leis foram resumidas no artigo 26 da Lei de Diretrizes e Bases da Educação Nacional (LDB).

Contudo, não são somente estes os documentos referentes às questões étnico-raciais no país. É valoroso analisar outros vieses, como os Parâmetros Curriculares Nacionais, aliados ainda à literatura já desenvolvida sobre o tema, que muitas vezes se encaminham para a História, fazendo necessária a aproximação com a Geografia, visto que a lei fala no ensino das questões indígenas em todos os componentes curriculares da educação básica.

Neste contexto, a lei é essencial para ampliar um debate ainda incipiente nas salas de aula, mostrando culturas e realidades invisibilizadas num currículo ainda colonizado. Assim, a lei 11.645/2008, sintetizada no artigo 26 da LDB, contribui na compreensão da multiculturalidade brasileira.

Nesse contexto, este trabalho tem a pretensão de discutir os principais instrumentos jurídicos e as ações desenvolvidas pelo Estado de Pernambuco para a efetiva implementação do tema história e cultura indígena nas escolas da rede estadual de educação e analisar seus desdobramentos no ensino de Geografia, salientando principalmente as perspectivas de professores/as da disciplina e coordenadores/as de escolas e secretarias de educação da Região Metropolitana do Recife.

Para isso, foi necessária, além da pesquisa bibliográfica, uma pesquisa documental, realizada nos órgãos responsáveis por implementar a lei em questão. Além disso, foram realizadas entrevistas com sujeitos considerados relevantes para o trabalho. Desse modo, foi possível dialogar com informações da literatura acadêmica, dos documentos analisados e daqueles/as que trabalham com a lei $11.645 / 2008$.

Este trabalho está estruturado em cinco seções. A primeira traz um resumo histórico de movimentos sociais e eventos acadêmicos que contribuíram na criação da lei através de importantes discussões. A segunda seção trata da lei em

Estudos Geográficos, Rio Claro, 17(1): 217-233, jan./jun. 2019 (ISSN 1678-698X) http://www.periodicos.rc.biblioteca.unesp.br/index.php/estgeo 
Pernambuco, salientando a importância da temática História e Cultura Afro-brasileira e Indígena no estado. Na terceira seção são analisados os alicerces documentais a nível nacional e estadual, sobretudo as propostas de erradicação de preconceitos e racismos. A quarta seção mostra a percepção dos sujeitos entrevistados acerca da implementação da lei 11.645/2008, dado que são os/as responsáveis para que essa lei alcance os/as estudantes. A quinta seção são sugestões de abordagens da temática na disciplina de Geografia na educação básica, destacando possibilidades interdisciplinares de discutir o tema na sala de aula.

\section{NAS ENTRELINHAS HISTÓRICAS: OS MOVIMENTOS SOCIAIS NA CONSTRUÇÃO DA LEI 11.645/2008}

A lei 11.645/2008, que institui a obrigatoriedade do ensino da história e da cultura afro-brasileira e indígena na educação básica, surgiu para complementar a lei 10.639, institucionalizada em 2003 e que obriga o ensino da história e cultura afro-brasileira e africana.

A lei de 2008 advém de uma história de apelos e conflitos envolvendo os/as indígenas. Mesmo após decretos, leis e a criação da Fundação Nacional do Índio (FUNAI), em 1967, o índio não possuía uma forte expressão no cenário social do país, sempre visto como habitante da floresta e sem conhecimento do mundo "civilizado". Após a promulgação da Constituição de 1988, os povos indígenas alcançaram direitos que mudaram totalmente a situação deles no âmbito social, ainda mais com a participação mais efetiva dos vários movimentos sociais que já ocorriam desde o início da década de 1980 (SILVA, 2016).

Nesse mesmo período iniciaram-se, em vários locais do país, movimentos indígenas relacionados à luta por terras, especialmente nas regiões Centro-Oeste e Nordeste. Ambos os casos estão relacionados à conflitos com fazendeiros. $O$ primeiro tem uma origem mais recente, dada a exploração tardia da região, envolvendo os/as indígenas e os proprietários do agronegócio, donos de grandes porções de terra que são reivindicados pelos índios dessas regiões. (FERRAZ; NUNES, 2012). O caso nordestino tem origem ainda no século XVI, quando a monocultura canavieira se instaura na região. A expansão das terras para o cultivo da cana de açúcar foi expulsando os/as indígenas de seu lugar, sendo que muitos povos indígenas do litoral foram extintos nesse processo (PRADO JÚNIOR, 2012) e hoje os povos remanescentes lutam para reconquistar a terra ou permanecer nela.

Esses dois processos auxiliaram na construção de uma identidade indígena, principalmente entre os índios "desaldeados", moradores urbanos afastados de seus territórios e que muitas vezes não se consideravam indígenas. A partir da Constituição de 1988 e das mobilizações, muitas pessoas se reconheceram como indígenas e fomentaram os movimentos sociais na busca por direitos.

No que tange a educação, os/as indígenas conseguiram o direito de ter uma educação diferenciada dentro de suas aldeias, conforme está no artigo 26 da Lei de Diretrizes e Bases da Educação Nacional (LDB): "§ $3^{\circ} \mathrm{O}$ ensino fundamental regular será ministrado em língua portuguesa, assegurada às comunidades indígenas a utilização de suas línguas maternas e processos próprios de aprendizagem" (BRASIL, 2014, p. 23). Entretanto, os índios "desaldeados" e os que não estudam em suas aldeias não estariam inclusos nessa educação diferenciada, portanto desconheceriam a história de seus povos.

Estudos Geográficos, Rio Claro, 17(1): 217-233, jan./jun. 2019 (ISSN 1678-698X) http://www.periodicos.rc.biblioteca.unesp.br/index.php/estgeo 
Ana Cláudia Silva (2016) afirma que a lei de 2008 é fruto de várias reivindicações antigas, movimentos históricos em busca de uma educação diferencial. Grupioni (2004) cita o I Encontro Estadual de Educação Indígena do Mato Grosso, em 1989, no qual professores/as indígenas pediram uma educação que combatesse a discriminação. Silva (2016) cita ainda o I Encontro dos Professores Indígenas de Rondônia, em 1990, onde foi solicitado respeito aos índios nas escolas não indígenas. A Declaração de Princípios dos Professores Indígenas do Amazonas, Roraima e Acre, em 1994, foi também muito importante. "O documento refere-se a diversas reivindicações antigas daqueles povos e sinaliza a importância de uma aproximação dos diversos segmentos da sociedade com a cultura indígena por meio da educação" (Ibidem, p. 88)

Percebe-se que a lei 11.645/2008 foi instituída a partir de um contexto de leis e documentos anteriores, incluindo a própria Constituição de 1988, além da atuação de movimentos sociais, que pressionaram os órgãos públicos na busca por direitos básicos e o reconhecimento dos chamados povos tradicionais. A lei, então, efetiva, ao menos na teoria, as discussões que foram se estabelecendo durante o último quartel do século $X X$, bem como as próprias ações dos povos indígenas, mostrando que não estão extintos, como muitos pensam, mas sim estão atuando incessantemente no contexto social e são, por vezes, invisibilizados.

\section{VALORIZAÇÃO DOS POVOS: IMPORTÂNCIA DO ESTUDO DA TEMÁTICA INDÍGENA À LUZ DOS ESTUDOS DECOLONIAIS}

Pernambuco possui uma das maiores populações indígenas do país, sendo bastante presente nas reivindicações políticas acerca do povo indígena. Entretanto, a temática indígena nas salas de aula pernambucanas não é tão evidente, uma contradição gritante.

Uma das abordagens em que essa pesquisa se fundamentou foi a perspectiva decolonial. Santos e Meneses (2009) trazem a ideia de valorizar o conhecimento, os saberes do Sul, que muitas vezes passam despercebido pelos estudiosos que utilizam os "clássicos" ocidentais.

Inocência Mata (2014) diz que há uma "colonização" invisível e inconsciente. A influência ocidental ainda está no meio, porém é imperceptível em alguns casos. A autora ainda afirma que essa inconsciência é um obstáculo que impede a construção de novos saberes que visem o Sul ou ainda estudos que explorem essas vertentes.

Ferreira e Silva (2013) questionam a presença hegemônica ocidental nos currículos, que valorizam um mesmo fenótipo, negligenciando as diversidades de etnias, culturas e costumes que os diferentes lugares possuem. Segundo os autores,

A presença do eurocentrismo nos currículos escolares, ou seja, a herança colonial ultrapassa o período do colonialismo e chega aos nossos dias como "história universal". Além de contar apenas uma versão da história, silenciando tantas outras, busca-se negar as diferenças, cristalizar identidades e manter a hegemonia de um único padrão estabelecido como "normal": o branco, o masculino, o heterossexual, o cristão, o urbano (Ibidem, p. 4).

Estudos Geográficos, Rio Claro, 17(1): 217-233, jan./jun. 2019 (ISSN 1678-698X) http://www.periodicos.rc.biblioteca.unesp.br/index.php/estgeo 
Como afirma Andrade (2009, p. 166), "A escola chegou, nossas crianças estudam a história dos brancos e esquecem nossa própria história". Assim, os/as indígenas que estudam nas cidades acabam por desconhecer ou esquecer sua cultura, sua história e ficam permeabilizadas pelas histórias ocidentais.

Corroborando com o autor supracitado, Queiroz (2011, p. 146) esclarece ainda que "[...] a escola, para o índio, é o lugar onde se deve aprender a cultura do branco, logo, o lugar onde se adquire conhecimento acerca do mundo do branco, e, para isso, incontornavelmente, esquece-se o conhecimento produzido pela 'cultura do índio"'. Por exemplo, deuses egípcios e gregos são ensinados nas escolas, porém as entidades indígenas dos mais diversos povos não são conhecidas ou discutidas em sala.

Conforme os Parâmetros Curriculares Nacionais (PCN), este diálogo em sala de aula contribuirá na formação da identidade e no conhecimento e valorização das diversas culturas, agindo para que os diferentes povos existentes no país conheçam a si mesmos e aos demais.

Como expressão de identidade nacional, a estética da sensibilidade facilitará o reconhecimento e a valorização da diversidade cultural brasileira e das formas de perceber e expressar a realidade própria dos gêneros, das etnias e das muitas regiões e grupos sociais do País. (BRASIL, 2000, p. 63, grifos do autor)

A lei 11.645/2008 contribui ainda na negação da "educação bancária" duramente criticada por Paulo Freire (1996), pois ela propicia uma mudança no currículo e consequentemente uma discussão que vai além do tradicionalismo.

Silva e Silva (2018) em estudo sobre a produção bibliográfica acerca da lei 11.645/2008 no Brasil enaltecem a relevância de refletir sobre esta temática. Segundo os autores: "[...] a maioria das pesquisas expostas indicou que as narrativas sobre os povos indígenas, originárias do contexto escolar, permanecem carregadas de preconceitos e estereótipos, seja por parte de estudantes seja dos/as professores/as [...]" (Ibidem, p. 44). Tanto no currículo como nos próprios sujeitos dos processos de ensino se notam preconceitos e falta de informações sobre os povos indígenas.

Nesse sentido é que a lei 11.645/2008 torna-se tão importante. Universalizar os conhecimentos sobre os povos indígenas não significa apenas propiciar àqueles que não estão em sua aldeia os saberes tradicionais que nelas seriam acessíveis, mas também mostrar aos não índios a pluralidade étnica existente no Brasil e, ainda, propiciar uma educação que fuja dos padrões ocidentais de ensino, contribuindo para o fim das discriminações étnico-raciais no país e da ideia de homogeneização entre os povos indígenas, pois são 305 etnias existentes no Brasil (SILVA, 2016).

\section{"LEIS DE MAQUIAGEM?"}

Em meio a todas as questões citadas sobre a lei 11.645/2008 ainda surgem algumas dúvidas. A lei fala sobre história e culturas afro-brasileiras e indígenas, um tema que pode ser tratado facilmente na disciplina de História e na Literatura, mas que também deve tanger todas as áreas de conhecimento, inclusive a Geografia, como indica o artigo 26 da LDB:

Estudos Geográficos, Rio Claro, 17(1): 217-233, jan./jun. 2019 (ISSN 1678-698X) http://www.periodicos.rc.biblioteca.unesp.br/index.php/estgeo 
$\S 2^{\circ}$ Os conteúdos referentes à história e cultura afro-brasileira e dos povos indígenas brasileiros serão ministrados no âmbito de todo o currículo escolar, em especial nas áreas de educação artística e de literatura e história brasileiras (BRASIL, 2014, p. 21).

O caráter geográfico, embora não seja falado diretamente, torna-se mais evidente no inciso que antecede o citado anteriormente.

§1 O conteúdo programático a que se refere este artigo incluirá
diversos aspectos da história e da cultura que caracterizam a
formação da população brasileira, a partir desses dois grupos
étnicos, tais como o estudo da história da África e dos africanos, a
luta dos negros e dos povos indígenas no Brasil, a cultura negra e
indígena brasileira e o negro e o índio na formação da sociedade
nacional, resgatando as suas contribuições nas áreas social,
econômica e política, pertinentes à história do Brasil (BRASIL, 2014,
p. 21).

Nota-se como a Geografia está presente nos temas propostos. A formação territorial (eis um conceito básico da disciplina) do país teve/tem influência dos indígenas, que estão presentes na sociedade dita civilizada, porém são invisibilizados. A questão econômica na agricultura, no qual fazendeiros latifundiários estão invadindo territórios indígenas, gerando conflitos socioespaciais. Pode-se ainda falar sobre a localização dos povos indígenas e as relações com as cidades (quando estão localizadas na área rural) ou as fronteiras territoriais de cultura (nas localidades urbanas), entre tantas outras possibilidades.

Os Parâmetros Curriculares Nacionais, numa discussão anterior à lei 11.645/2008, salientam a importância da discussão das relações étnico-raciais na sala de aula, uma vez que "possibilita a ampliação dos saberes, sem retirá-los da sua historicidade e, no caso do Brasil, de interação entre nossas diversas etnias, com as raízes africanas, indígenas, européias e orientais" (BRASIL, 2000, p. 90).

As Diretrizes Curriculares Nacionais Gerais da Educação Básica salientam as dificuldades das escolas em atender as minorias no país, envolvendo-os num processo inclusivo no âmbito escolar. Segundo o documento:

Exige-se, pois, problematizar o desenho organizacional da instituição escolar, que não tem conseguido responder às singularidades dos sujeitos que a compõem. Torna-se inadiável trazer para o debate os princípios e as práticas de um processo de inclusão social, que garanta o acesso e considere a diversidade humana, social, cultural, econômica dos grupos historicamente excluídos. Trata-se das questões de classe, gênero, raça, etnia, geração, constituídas por categorias que se entrelaçam na vida social - pobres, mulheres, afrodescendentes, indígenas, pessoas com deficiência, as populações do campo, os de diferentes orientações sexuais, os sujeitos albergados, aqueles em situação de rua, em privação de liberdade - todos que compõem a diversidade que é a sociedade brasileira e que começam a ser contemplados pelas políticas públicas (BRASIL, 2013, p. 16).

O documento ainda trata da importância do debate étnico-racial (e social também) na sala de aula para a formação de cidadãos que respeitem e

Estudos Geográficos, Rio Claro, 17(1): 217-233, jan./jun. 2019 (ISSN 1678-698X) http://www.periodicos.rc.biblioteca.unesp.br/index.php/estgeo 
compreendam as diversidades e convivam com elas sem preconceito. Ele afirma que:

Na formação de pequenos cidadãos compromissada com uma visão plural de mundo, é necessário criar condições para o estabelecimento de uma relação positiva e uma apropriação das contribuições histórico-culturais dos povos indígenas, afrodescendentes, asiáticos, europeus e de outros países da América, reconhecendo, valorizando, respeitando e possibilitando 0 contato das crianças com as histórias e as culturas desses povos (Ibidem, p. 89).

Bergamashi e Gomes (2012, p. 55) corroboram com o debate sobre o diálogo intercultural entre indígenas e não indígenas, salientando a questão educacional. Segundos os autores:

[...] a proposta educacional é conviver e efetuar trocas com as sociedades indígenas, a escola terá que fazer um esforço para conhecer esses povos, sua história e sua cultura e, mais especialmente, afirmar uma presença que supere a invisibilidade histórica que se estende até o presente.

Nesse contexto, a educação pode ser vista como mediadora entre um povo invisibilizado na sociedade (e às vezes dado como extinto) e uma maioria social que os inferiorizou durante séculos, o que é o caso dos povos indígenas. Através da educação pode-se haver a troca de conhecimentos únicos e próprios de povos específicos com os saberes ocidentais que perpetuam os currículos das escolas básicas. Desse modo, haverá uma menor incidência da hegemonia ocidental e uma valorização dos saberes locais, tal como preza os estudos decoloniais tratados na seção anterior.

Assim, a escola não pode ser um ambiente segregacionista e que perpetue um tratamento desigual dos/as estudantes a partir de uma homogeneização ocidental, como aponta Silva (2016), mas sim um ambiente acolhedor e que trate as diferenças étnicas e sociais no país sem um caráter discriminatório, para a formação de cidadãos críticos e que compreendam e respeitem tais diferenças sem se colocar como superior ou inferior.

Em Pernambuco, segundo Silva (2012) a aplicação da Lei 11.645/2008 se deu de forma inusitada. Em vez de incluir a História e cultura afro-brasileira e indígena nos componentes curriculares já existentes, foram criadas disciplinas especificamente para atender à lei: "Educação, direitos humanos e cidadania" e "História da Cultura Pernambucana".

Todavia, há de considerarmos que o arranjo pernambucano tendeu a fugir das prescrições estabelecidas na Lei. Como expresso em seu texto, estes conteúdos deveriam ser tratados, especialmente, nas áreas de Artes, Literatura e História. Entretanto, no referido estado as temáticas afro-indígenas não ocuparam o lugar conquistado legitimamente nas áreas de Artes, Literatura e História, antes, foram incorporadas aos dois novos componentes curriculares. (SILVA, $2012, n / p)$.

Estudos Geográficos, Rio Claro, 17(1): 217-233, jan./jun. 2019 (ISSN 1678-698X) http://www.periodicos.rc.biblioteca.unesp.br/index.php/estgeo 
A Secretaria de Educação forneceu a Instrução Normativa no 4/2011. O documento nada mais é que um compilado com as informações já constadas na lei 11.645/2008. As mudanças são na questão da responsabilidade. A Secretaria de Educação se compromete a gerir as questões relacionadas a temática indígena ${ }^{3}$ na educação básica, porém, como será descrito na próxima seção, esta não é uma realidade.

Desse modo, Pernambuco não atendeu, de fato, a lei, criando assim disciplinas para tentar atender às exigências da lei. Porém, essas novas disciplinas não atendem à função da lei de inserir a temática indígena e afro-brasileira nos componentes curriculares, apenas separou ainda mais as questões indígenas e os conteúdos da "escola de branco", não permitindo o tão importante diálogo entre essas partes.

\section{DA LEI PARA A SALA DE AULA: A PERCEPÇÃO DE PROFESSORES/AS DE GEOGRAFIA E COORDENADORES/AS ACERCA DA TEMÁTICA HISTÓRIA E CULTURA INDÍGENA}

Nesta seção, são debatidas as visões daqueles que são responsáveis pela discussão da temática, pois como afirma Silva e Silva (2018, p. 45):

[...] as práticas curriculares docentes constituem-se para além da tradição curricular, reconfigurando-se cotidianamente nas relações pessoal e profissional do/a professor/a com os conhecimentos tradicionais do currículo. Também nas relações do/a professor/a, com suas percepções do mundo, sobre a sociedade local, o ambiente escolar, a sala de aula e o público estudantil.

Primeiramente vale ressaltar a ausência, na Secretaria de Educação do Estado de Pernambuco, de um núcleo ou departamento que trate a questão indígena em escolas não indígenas, havendo apenas uma superintendência dedicada à educação indígena. O setor responsável pela temática deveria ser 0 Núcleo de Direitos Humanos, mas, como será evidenciado posteriormente, o discurso é essencialmente voltado a questão da temática afro-brasileira.

Dessa forma, as análises seguirão uma hierarquia de acordo com a ordem em que a temática é tratada, ou seja, o Núcleo de Direitos Humanos, os Coordenadores das escolas entrevistadas e os/as professores/as destas escolas. Esta ordem não interfere que os discursos sejam comparados quando necessário.

Segundo o entrevistado E1 (mar. $2018^{4}$ ), da Secretaria de Educação, o Governo atua em relação à temática étnico-racial através do currículo, dos cursos de formação e do material didático. O currículo é relacionado a inseminação da temática nas grades curriculares das escolas. Os cursos de formação ocorrem frequentemente e dão suporte para os/as professores/as trabalharem a temática com seus/suas estudantes. O material didático, por fim, deve ser incorporado por conteúdos relacionados a cultura e história indígena. Os documentos disponíveis na

\footnotetext{
${ }^{3}$ Vale aqui fazer uma distinção entre Educação Indígena e ensino da temática indígena. Educação indígena refere-se ao ensino feito em escolas indígenas. Essa área é bem abordada pela Secretaria de Educação, possuindo superintendência própria. A temática indígena na educação básica, foco deste trabalho, não possui superintendência ou departamentos próprios na instituição.

${ }^{4}$ Coordenador da Secretaria de Educação de Pernambuco, responsável pelo Núcleo de Direitos Humanos.

Estudos Geográficos, Rio Claro, 17(1): 217-233, jan./jun. 2019 (ISSN 1678-698X) http://www.periodicos.rc.biblioteca.unesp.br/index.php/estgeo
} 
Secretaria de Educação norteiam a discussão da temática, porém, como foi visto, elas mascaram o real objetivo da lei 11.645/2008.

Uma das atuações principais do poder público é a mudança nos Parâmetros Curriculares, na qual o entrevistado diz:

Referente aos Parâmetros Curriculares, nos diferentes componentes curriculares que estão inseridos nessa temática também trabalhamos essa temática. Isso quer dizer que o professor de diferentes componentes curriculares: Geografia, História, Química, Física, Biologia, Ciências, Matemática, Língua Portuguesa, enfim, tanto da educação do ensino fundamental anos finais quanto no ensino médio, que esteja interessado e queira referenciais para trabalhar essa temática, ele tem. Tem dois aspectos. Primeiro o conteúdo, em que conteúdo ele pode fazer essa abordagem. Nesse conteúdo está indicada a série e o período para a abordagem. E tem também a expectativa de abordagem, que é a meta do professor em sala de aula. Concluímos isso em 2013, 2014 e hoje está disponível para qualquer professor (E1, mar. 2018).

Um comentário pertinente a se fazer sobre a fala em questão é o uso do termo "interessado", que dá a ideia de que o/a professor/a possa optar entre trabalhar ou não a temática, quando ele na verdade deve trabalhar a temática, segundo a lei 11.645/2008. O documento citado está disponível no site da Secretaria de Educação do Estado de Pernambuco e, como citado na seção anterior, fala superficialmente sobre a questão indígena.

Quando se afunila o tema para a questão indígena, o entrevistado afirma que:

Há um diferencial, aqui nós temos a Superintendência Indígena. Ela trabalha com a educação indígena, mas também com a temática indígena. É um pouco dissociado de nosso trabalho do ponto de vista que se trabalha em outro departamento, não especificamente no núcleo de educação étnico-racial. Isso não impede, por exemplo, de vez ou outra a gente está dialogando não só com a SUPIN como alguns professores e pessoas da universidade. Isso vai depender da demanda, às vezes temos problemas para marcar com pessoas para trabalhar essa questão indígena. Mas, assim, o grosso mesmo que a gente trabalha é a cultura afro-brasileira e africana (E1, mar. 2018).

Nota-se a incipiência da discussão da temática indígena no cenário da Secretaria de Educação visto os debates são focadas na questão afro-brasileira. Contudo, como se trata de um Núcleo de Direitos Humanos, outras realidades deveriam ser trabalhadas, especialmente a indígena, dado o contingente populacional do estado. Outros funcionários corroboram ao afirmar a ênfase do núcleo na abordagem afro-brasileira ${ }^{5}$.

Quanto aos projetos, foi dito que não há projetos específicos para a temática, há apenas os cursos de formação onde estes assuntos são trabalhados. Uma das professoras entrevistadas confirmou esta informação e disse que "Eles [a

\footnotetext{
${ }^{5}$ A questão afro-brasileira também é tratada de forma incipiente dentro do contexto das escolas básicas, porém quando comparada aos estudos sobre povos indígenas nota-se que são mais recorrentes, enquanto os indígenas são praticamente invisibilizados.

Estudos Geográficos, Rio Claro, 17(1): 217-233, jan./jun. 2019 (ISSN 1678-698X) http://www.periodicos.rc.biblioteca.unesp.br/index.php/estgeo
} 
Secretaria de Educação] não incentivam muito a trabalhar a temática indígena" (E2, abr, $\left.2018^{6}\right)$.

Uma das preocupações trazidas pelo entrevistado da Secretaria de Educação é a questão intercultural e a prática contínua desta temática. Segundo ele:

\begin{abstract}
Nossa preocupação é que ao fazer essa abordagem o professor não traga apenas elementos da cultura, mas que ele passe a redimensionar essa herança brasileira na sua própria prática pedagógica. E aí se pode estimular o professor a trabalhar esse assunto durante todo ano letivo [...]. O problema é que muita gente acha que trabalhar cultura afro-brasileira e africana é trabalhar uma atividade cultural, botar os meninos pra dançar maracatu, vão dançar algumas danças específicas ou características da população afrodescendente aqui no Brasil e acham que isso é fazer a coisa acontecer. A gente trabalha com outra dimensão: a dimensão de que estes elementos sejam incorporados aos conteúdos. Assim, a garantia de que o professor pratique a lei durante o ano é maior ( $E 1$, mar. 2018).
\end{abstract}

Uma professora citou que trabalha com interdisciplinaridade: "Eles [a Secretaria] pedem. Toda vez que a gente está nas formações eles pedem para trabalhar com a questão da interdisciplinaridade. Quando a gente faz os projetos aqui na escola, nós englobamos todas as disciplinas" (E3, mar. 2018) ${ }^{7}$.

Já uma coordenadora entrevistada, com vasta experiência profissional em diversos seguimentos da educação, cita não uma proposta interdisciplinar, mas sim uma proposta interdimensional. Segue a fala dela:

Dentro da proposta do integral a gente trabalha não só a interdisciplinaridade, mas um viés do integral é a interdimensionalidade. A interdisciplinaridade é as disciplinas dentro de uma mesma meta, de um mesmo objetivo, dentro de um projeto. Já a interdimensionalidade tem a ver com o conhecimento, 0 conhecimento que é interdimensionado. O integral trabalha principalmente a interdimensionalidade do conhecimento. Não é um conhecimento parado, mas ele se relaciona (E4, abr. 2018) ${ }^{8}$.

A partir das falas podemos observar que a interdisciplinaridade/ interdimensionalidade se adequa muito bem à temática étnico-racial. Outra vez notase o discurso enfático à questão afro-brasileira na primeira fala, mas se pode notar que para a efetiva aplicação da lei é necessário que as disciplinas trabalhem 0 conteúdo de forma contínua.

Duas dificuldades que, na opinião do entrevistado, são grandes obstáculos na execução da lei são o racismo institucional e a democracia racial. Segundo ele,

Há também o racismo institucional na nossa sociedade. Os gestores não encaram a temática étnico-racial como importante em nossa educação. Apesar de alguns momentos nós termos conseguido inserir esta temática, o racismo institucional é muito estruturante. Há aquela ideia do velho dito da democracia racial, como aqui não há

\footnotetext{
${ }^{6}$ Professora de Geografia em escola estadual na cidade de Recife.

7 Professora de Geografia em escola estadual no município de Paulista.

${ }^{8}$ Coordenadora de apoio em escola estadual no município de Paulista, entre outras funções.

Estudos Geográficos, Rio Claro, 17(1): 217-233, jan./jun. 2019 (ISSN 1678-698X)

http://www.periodicos.rc.biblioteca.unesp.br/index.php/estgeo
} 
um pensamento racial que seja suficiente para combater isso, pelo contrário há uma ideia que aqui as questões raciais estão devidamente resolvidas, todo mundo é igual, todo mundo é miscigenado, todo mundo é de uma mesma raça, da mesma concepção humana, fica difícil resolver questões específicas de uma população que historicamente vêm sendo descriminada em todos os aspectos. Não é exclusivo da educação, mas como é estruturante na sociedade brasileira acaba rebatendo (E1, mar. 2018).

O entrevistado traz então duas questões importantes que possuem escalas micro e macro, porém uma interferindo na outra. $O$ racismo institucional dentro de uma escala micro, como a Secretaria da Educação, tem consequência direta na escala macro da educação no estado. Dessa forma, a temática étnico-racial (o entrevistado não cita a questão indígena especificamente, sempre utilizando termos relacionados ao afro-brasileiro ou étnico-racial) acaba por não ser debatida nas escolas, uma vez que as próprias instituições por vezes a negligenciam. Já a democracia racial vem para negar a importância desta temática, as diversidades, os valores que os estudos decoloniais tanto exaltam. Além do mais, estes problemas omitem os preconceitos e as discriminações existentes na sociedade ao tratar as etnias como iguais.

Quanto aos resultados dos cursos de formação e da atuação do núcleo, o entrevistado foca bastante na identidade negra como um fator de satisfação dos/as estudantes. As iniciativas da Secretaria de Educação culminaram em prêmios para a educação em Pernambuco, incentivando o aprimoramento e manutenção do trabalho realizado.

O coordenador cita ainda que não há um trabalho específico por disciplina, sendo destinado apenas aos cursos de formação as orientações sobre os temas. Uma das professoras, sobre a importância da temática na Geografia diz que "No terceiro ano, quando eu trabalho as migrações, falo sobre essa questão dos negros, como chegaram aqui; a questão dos refugiados, os conflitos. É assim que trabalho com eles" (E1, mar. 2018).

O coordenador da Secretaria de Educação, sobre esse assunto, ressalta:

A gente cria estratégias com o professor que trabalha interdisciplinar. No ensino fundamental a gente trabalha a diáspora africana no Brasil. A gente aborda as Artes na questão do maracatu, por exemplo; as Ciências com a culinária e a medicina africana. Quando chega na Geografia, a gente trabalha com os quilombos e a resistência dos negros aqui no Brasil. É uma abordagem que a gente faz no que a gente entende como a diáspora africana aqui no Brasil. O professor de Geografia vai trabalhar este tema junto com outras disciplinas para que tenha uma visão macro, uma visão geral daquilo que a gente entende como história africana. Aí, por exemplo, quando o professor de Geografia vai trabalhar a questão dos quilombos, como ele vai fazer a abordagem? A dinâmica do território brasileiro, a população brasileira, a formação da população brasileira e nisto vai inserir a questão africana. Isso está escrito nos parâmetros curriculares. [...] Geografia vai trabalhar também as análises de dados, em matemática vai estar a criação dos dados, a construção de gráficos, em Geografia será a interpretação dos indicadores sociais da população branca e da população negra. Ou seja, quando

Estudos Geográficos, Rio Claro, 17(1): 217-233, jan./jun. 2019 (ISSN 1678-698X) http://www.periodicos.rc.biblioteca.unesp.br/index.php/estgeo 
a gente faz a abordagem a gente não atende especificamente uma disciplina (E1, mar. 2018).

Nota-se nas duas falas como a questão indígena é sobrepujada pela questão negra. Quando se fala de relações étnico-raciais o pensamento tanto de professores/as como de coordenadores/as é voltado para a diáspora e para formação territorial a partir de afro-brasileiros. No entanto, este são assuntos que também se aplicam às questões indígenas, como os Territórios Indígenas ${ }^{9}$, os conflitos da agropecuária e tantos outros temas possíveis aos estudos e que seguem despercebidos no âmbito educacional.

Coordenadores/as e professores/as das escolas concordam que essa temática é muito importante na superação dos preconceitos. Uma das professoras, que também ministra aula de Sociologia e outras disciplinas, fala que a temática "É importante porque em Sociologia a gente trabalha diversos grupos sociais, então é importante trabalhar isso para acabar com essas questões de preconceito. Trabalhar com os meninos isso em sala de aula." (E5, abr., 2018 ${ }^{10}$ ). O coordenador da Secretaria de Educação, embora focado na questão afro-brasileira, traz um discurso pertinente sobre a importância da lei não só como uma questão própria da educação, mas também de um contexto social, salientando que este é o grande objetivo e desafio da lei ${ }^{11}$.

Assim, toda formação que a gente faz a gente sempre traz não só os documentos daqui do estado, mas também nacionais. Eu sempre digo: o desfio nosso não é implementar a lei, é implementar as diretrizes, porque a lei a rigor as escolas implementam. Se chegar em qualquer escola nossa e perguntar, a grande maioria vai dizer que implementam a lei, porque trabalham com a temática. Mas nosso desafio é implementar as diretrizes, aquilo que está além da lei. Não é apenas dar o conteúdo, é incorporar ao conteúdo esses valores civilizatórios, esse é nosso desafio. Está previsto nas diretrizes e na nossa normativa e eu sou sincero, não encontro isso nas escolas pelo Brasil, vejo a lei, mas não as diretrizes. Eu não quero ter um aluno que faça uma prova da história da África, ou da Geografia da África e ele possa identificar que a África tem 54 países; que o Egito não é Oriente Médio, é África; que tem a África do Norte que é tão diversificada quando a África do Sul; que ele aprenda isso, mas continue chamando seu coleguinha de macaco, negrinho, "nêgo" fedido. Não é só aprender sobre o continente e história da África, é aprender também novas concepções para lidar com relações raciais para que dentro da escola e também dentro da sociedade brasileira a gente não tenha mais este tipo de educação racista. Outra coisa, essa lei não é só para os negros não, é também para os não negros. Não para o negrinho se encher de autoestima e se sentir que ser negro é o dez, mas também para que o branco deixa de ser racista. (E1, mar. 2018)

O entrevistado sintetiza bem o caráter socioeducacional da lei 11.645/2008 ao discutir que as temáticas não devem ficar restritas ao ambiente da sala de aula.

\footnotetext{
${ }^{9}$ Optou-se pelo termo Território Indígena a Terra Indígena, pois as interações entre indígenas e aquele espaço é repleto de símbolos que mostram as relações de poder características de um território.

${ }^{10}$ Professora de História, Geografia, Filosofia, Sociologia e Artes em escola estadual no município de Paulista.

${ }^{11}$ Neste ponto se fala da lei 10639/03, que permeia a fala do entrevistado, e não da lei 11.645/08.

Estudos Geográficos, Rio Claro, 17(1): 217-233, jan./jun. 2019 (ISSN 1678-698X) http://www.periodicos.rc.biblioteca.unesp.br/index.php/estgeo
} 
Estes estudos devem contribuir na formação de seres pensantes que reflitam e enxerguem a diversidade de povos e etnias dentro do país, cada qual com sua importância e lugar na sociedade, e percebam que esta riqueza étnica está associada a uma miríade de valores e saberes de culturas próprias, mas que muitas vezes estão dispersos na sociedade e não são notados.

Dessa forma, o objetivo principal não é saber o número de indígenas no país, que em Pernambuco existem 13 etnias, ou que há pelo menos 16 povos isolados. O cerne da lei é promover a compreensão que o/a indígena está próximo, é um agente formador do território e da sociedade brasileira, que não é uma criatura pura e das matas, um herói do Brasil, tal qual diziam os autores românticos. Incluir a temática no currículo sem o suporte social que deveria ter é uma atitude vazia, desprovida dos reais significados que a lei traz.

\section{PARA ALÉM DAS DATAS COMEMORATIVAS: SUGESTÕES PARA O ENSINO CONTÍNUO DA TEMÁTICA NO ENSINO DE GEOGRAFIA}

Como já foi evidenciado por vários dos autores citados anteriormente e também nas entrevistas, a temática indígena é muitas vezes tratada apenas no Dia do Índio ${ }^{12}$, quando na verdade deveria ser um trabalho contínuo durante o ano. Outra dificuldade é relacionada à falta de preparo dos/as professores/as, que acabam caindo no lugar-comum ao tratar o tema em sala.

Silva e Silva (2016, p. 154) trazem sugestões de uso da lei em diferentes disciplinas, incluindo as disciplinas "duras", como Geometria e as Ciências Exatas. Os autores afirmam que "pensando a interculturalidade como uma via de mão dupla, a Educação deve possibilitar o intercâmbio de conhecimentos, a troca, o diálogo, a igualdade de direitos e de oportunidades". Assim, inserir efetivamente os saberes relacionados aos povos indígenas em todas as áreas de conhecimentos da Educação Básica é de profunda importância para a formação dos indivíduos. Quanto à Geografia, os autores sugerem "localizar os territórios indígenas contemporâneos, as condições climáticas, as formas de manejo dos recursos naturais, os conflitos agrários e suas consequências" (Ibidem, p. 154).

Pode-se incluir aqui também estudos sobre os municípios indígenas, a presença de indígenas nas grandes cidades, e todo um sem-número de variáveis possíveis e atuais, mas que muitas vezes são simplesmente invisibilizadas no contexto social.

Os conceitos básicos da Geografia também corroboram para a questão indígena na sala de aula, podendo-se destacar principalmente território e territorialidade, uma vez que por menor que uma aldeia possa ser ela possui um território e exerce uma territorialidade importante e deve ser estudada no que trata ao conhecimento geográfico (BRASIL, 2000).

Outros temas em que a história e cultura indígena poderiam ser notáveis seriam os estudos sobre as religiões no espaço brasileiro, destacando a heterogeneidade cultural no Brasil; a própria população brasileiras, enaltecendo as origens indígenas tanto no social como no urbano; o agronegócio e os conflitos em terras indígenas; as migrações, visto que muitos/as indígenas saíram de suas

\footnotetext{
${ }^{12}$ Alguns povos indígenas de Pernambuco recusam esta data, dado ao caráter folclórico e estereotipado que ela possui. Estudos Geográficos, Rio Claro, 17(1): 217-233, jan./jun. 2019 (ISSN 1678-698X) http://www.periodicos.rc.biblioteca.unesp.br/index.php/estgeo
} 
aldeias em busca de empregos nas capitais, entre uma miríade de outros temas em que a questão indígena poderia ser relevantes.

As Orientações Curriculares para o Ensino Médio ampliam essa discussão ao afirmar que "a constituição cotidiana de territórios tem como base, as relações de poder e de identidade de diferentes grupos sociais que os integram, por isso eles estão inter-relacionados com conceitos de lugar e região" (BRASIL, 2006, p. 54). Ou seja, ao estudar os territórios indígenas, muitos dos conceitos básicos se correlacionam, podendo através de um único exemplo dialogar sobre aspectos étnico-raciais e as bases conceituais da Geografia. $O$ documento ainda salienta como esses territórios criam relações entre pessoas e povos, contribuindo na formação do território nacional, ao dizer que "são essas territorialidades que definem as relações entre as pessoas, entre as nações e entre os grupos sociais, os quais produzem e organizam o espaço de formas diferenciadas nos vários lugares e no tempo" (Ibidem, p. 59).

O ensino da Geografia relacionado às questões indígenas deve ser contextualizado, além disso, também é necessária a formação do senso crítico discente para que se finde a discriminação. Quanto a isso, Gabas (2017, p. 107), afirma que:

[...] a fim de abordar a questão indígena na disciplina de Geografia é necessário contextualizar as lutas, resistências e os desafios enfrentados por esses povos na atualidade, efetuando a análise dos impactos negativos dos empreendimentos capitalistas sobre os povos indígenas, instigando a reflexão, sensibilização e o senso crítico quanto à política indigenista e tratamento de questões étnicas no país, de forma que ao final os estudantes possam reconhecer a necessidade de atuar em defesa desses povos.

A autora defende ainda que estes debates sobre os/as indígenas na sala de aula devem ser feitos afastando-se da visão eurocêntrica e dos preconceitos criados a partir de tal visão. Seria algo como "aprender a desaprender", aprender "as histórias narradas por cada povo” (Ibidem, p. 105).

Apesar de haver tantas possibilidades, quando se trata a questão indígena durante uma aula de geografia ela aparece como algo muito breve e genérico, sem levar em consideração a diversidade existente já citada várias vezes. Até a própria imagem do índio é tendenciosa e simplista, mostrando sempre um homem imberbe, de cabelo liso e peito nu, com as partes íntimas cobertas por folhas ou palhas, 0 corpo pintado e na cabeça um cocar. Outra vez nota-se um desrespeito, talvez um desconhecimento, das diferenças que há entre os/as indígenas, o que contribui para aprofundar a discriminação existente.

Sendo assim, é importante também que a própria escola esteja preparada para a aplicação efetiva da lei 11.645/2008. Os/as docentes devem ter a sensibilidade para tratar estes assuntos de maneira não simplista nem homogênea, mostrando a riqueza étnica do país e de seus estados, principalmente os estados de grande população indígenas, como Amazonas, Mato Grosso do Sul, Bahia e Pernambuco.

Estudos Geográficos, Rio Claro, 17(1): 217-233, jan./jun. $2019 \quad$ (ISSN 1678-698X) http://www.periodicos.rc.biblioteca.unesp.br/index.php/estgeo 


\section{CONSIDERAÇÕES FINAIS}

Constatou-se nesta pesquisa que há um aporte documental no estado de Pernambuco que fundamentam a lei 11.645/2008, porém a efetiva aplicação nas escolas de educação básica do Recife e Região Metropolitana é questionável.

Os estudos decoloniais aparecem para propor uma rotura no currículo colonizado presente na maioria das escolas, reverberando no cotidiano dos sujeitos que vivenciam a realidade de pertencer aos grupos das minorias, de ser discriminado.

A lei 11.645/2008 irrompe a partir de muitas discussões e reinvindicações de movimentos sociais, porém ainda são necessárias mais discussões para que a temática História e Cultural Afro-brasileira e Indígena seja realmente implantada nas escolas e promova seu grande objetivo: superar as formas de preconceitos e racismo através do conhecimento do/a outro/a.

Em grande parte das escolas da Região Metropolitana do Recife, observa-se que a temática ainda se desenvolve de forma incipiente, mas a discussão afrobrasileira ainda é maior do que a indígena, muitas vezes resumida ao dia 19 de abril.

Nesse contexto, é importante uma revisão das práticas pedagógicas com o objetivo de evidenciar a importância dos povos indígenas, principalmente em Pernambuco, dada a sua grande população indígena, destacar suas características socioculturais e contribuir para a erradicação de pensamentos acerca de uma falsa homogeneidade indígena no Brasil.

\section{REFERÊNCIAS}

ANDRADE, Karenina V. Wätunnä: a força de uma profecia ye'kuana. Tellus, n. 17, p. 11-31, jul./dez. 2009.

BERGAMASHI, M. A.; GOMES, Luana Barth. A temática indígena na sala de aula: ensaios de educação intercultural. Currículo sem Fronteiras, v.12, n.1, p. 53-69, jan./abr. 2012.

BRASIL. Diretrizes Curriculares Nacionais Gerais da Educação Básica. Ministério da Educação. Secretária de Educação Básica. Diretoria de Currículos e Educação Integral. - Brasília: MEC, SEB, DICEI, 2013.

BRASIL. LDB: Lei de diretrizes e bases da educação nacional. 10ª ed. Brasília: Câmara dos Deputados, Edições Câmara, 2014.

BRASIL. Orientações Curriculares para o Ensino Médio. Ministério da Educação - MEC, Secretaria de Educação Básica, 2006. Disponível em: $<$ http://portal.mec.gov.br/seb/arquivos/pdf/book volume 03 internet.pdf $>$. Acesso em: 12 jan. 2018.

BRASIL. Parâmetros Curriculares Nacionais para o Ensino Médio. Ministério da Educação - $\quad$ MEC, 2000. Disponível em: <http://portal.mec.gov.br/seb/arquivos/pdf/cienciah.pdf $>$. Acesso em: 13 jan. 2018.

Estudos Geográficos, Rio Claro, 17(1): 217-233, jan./jun. $2019 \quad$ (ISSN 1678-698X) http://www.periodicos.rc.biblioteca.unesp.br/index.php/estgeo 
FERRAZ, Cláudio Benito Oliveira; NUNES, Flaviana Gasparotti. Identidade nacional e/ou territorial: conflito entre indígenas e fazendeiros no centro-oeste brasileiro. In: COLÓQUIO INTERNACIONAL DE GEOCRÍTICA, 12, 2012, Bogotá. Anais... Bogotá, 2012. p. 1-13.

FERREIRA, Michele Guerreiro; SILVA, Janssen Felipe da. Educação das relações étnico-raciais e as possiblidades de decolonização dos currículos escolares: 10 anos da lei oㅡ 10.639/2003. Interfaces de Saberes (FAFICA Online), v. 13, p. 4-22, 2013.

FREIRE, Paulo. Pedagogia da autonomia. São Paulo: Paz e Terra, 1996.

GABAS, Angélica dos Reis. O estudo das lutas, resistências e desafios enfrentados pelos povos indígenas na atualidade: aplicando a Lei $n^{\circ} 11.645 / 08$ na Geografia no Ensino Médio. Revista SURES, n. 9, p. 97-112, fev. 2017.

GRUPIONI, Luís Donizete Benzi. Educação e diversidade. In: SILVA, Aracy Lopes da; GRUPIONI, Luís Donizete Benzi (Orgs.). A temática indígena na escola: novos subsídios para professores de $1^{\circ}$ e $2^{\circ}$ graus. Brasília: MEC/MARI/UNESCO, 2004, p. 15-23.

MATA, Inocência. Estudos pós-coloniais: descontruindo genealogias eurocêntricas. Civitas, Porto Alegre, v. 14, n. 1, p. 27-42, 2014.

QUEIROZ, Ruben Caixeta de. Educação e pensamento indígena: da alfabetização aos territórios etnoeducacionais. In: FONSECA, Marcus Vinícius; SILVA, Carolina Mostaro Neves da; FERNANDES, Alexsandra Borges (Orgs.). Relações étnicoraciais e educação no Brasil. Belo Horizonte: Mazza Edições, 2011, p. 145-181.

PRADO JÚNIOR, Caio. História econômica do Brasil. São Paulo: Brasiliense, 2012.

SANTOS, Boaventura de Sousa; MENESES, Maria Paula (Orgs.) Epistemologias do Sul. Coimbra: Almedina, 2009.

SILVA, Ana Cláudia Oliveira da. A implantação da Lei 11.645/2008 no Brasil: um histórico de mobilizações e conquistas. In: SILVA, Edson; SILVA, Maria da Penha da (Orgs.). A temática indígena na sala de aula: Reflexões para o ensino a partir da Lei 11.645/2008. Recife: Ed. Dos Organizadores, 2016, p. 85-112.

SILVA, Ana Cláudia Oliveira da. A inserção curricular da história e cultura afrobrasileira e indígena na rede estadual de Pernambuco. In: COLÓQUIO LUSO BRASILEIRO DE CURRÍCULO, 4 / COLÓQUIO SOBRE QUESTÕES CURRICULARES, 10, 2012, Belo Horizonte. Anais... Belo Horizonte: UFMG, 2012.

SILVA, Edson; SILVA, Maria de Penha da. A Lei o 11.645/2008 problematizando o ensino da temática indígena e provocando possibilidades de pesquisa. In: NETA, Francisca Maria; PEIXOTO, José Adelson Lopes (Orgs.). Saberes compartilhados: múltiplos olhares na contemporaneidade. Recife: Libertas, 2018, p. 35-54.

Estudos Geográficos, Rio Claro, 17(1): 217-233, jan./jun. 2019 (ISSN 1678-698X) http://www.periodicos.rc.biblioteca.unesp.br/index.php/estgeo 
SILVA, Edson; SILVA, Maria da Penha da. As diversidades étnicas no Brasil: desafios às práticas escolares. In:

A temática indígena na sala de aula: Reflexões para o ensino a partir da Lei 11.645/2008. 2 ed. Recife: Ed. Dos Organizadores, 2016, p. 151-177.

SILVA, Maria da Penha da. Educação intercultural: a presença indígena nas escolas da cidade e a Lei 11.645/2008. In: SILVA, Edson; SILVA, Maria da Penha da. A temática indígena na sala de aula: Reflexões para o ensino a partir da Lei 11.645/2008. Recife: Ed. Dos Organizadores, 2016, p. 57-84. 